\title{
INFORMATION TRANSPARENCY:A MANAGERIAL PRACTICE TO ENHANCE EMPLOYEE ENGAGEMENT (AN EXPLORATIVE STUDY AT SELECTED HOTELS / ERBIL CITY)
}

\author{
DR. HADi Khalil Ismael and Green Mustafa AMEDI \\ Dept. Of Business Administration, College Of Administration And Economics, University Of Duhok, \\ Kurdistan-Iraq
}

(Received: June 28, 2018; Accepted for Publication: January 23, 2019)

\begin{abstract}
The purpose of this study is to investigate the role of information transparency as a managerial practice in enhancing employee engagement, in the context of hotels sector/ Erbil City. A survey self -administrated questionnaire was distributed on a sample of 80 managers in the supervisory departments of (12) five stars and four stars hotels.

The study concluded that there is a statistically significant impact of Information transparency on employee engagement at the overall level and on the dimensions of employee engagement (Emotional engagement, Cognitive engagement, Physical engagement) with default significance at $(P \leq 0.05)$.

The study presents a set of suggestions including the necessity of providing clear and two-way communication system between management and employees, and creating an organizational climate that encourages employees to participate in goals setting and decision-making.
\end{abstract}

KEY WORDS: Transparency, Information Transparency, Employee Engagement, Emotional Engagement, Cognitive Engagement, Physical Engagement

\section{INTRODUCTION}

$\mathbf{I}$ nformation transparency is a contemporary concept that is widely used today by business organizations as a result of the developments and changes in management practices such as communication technologies, information transfer speed and accessibility. This concept is concerned with making information transparent by disclosing information, providing employees with clear and confident information, as well as making it accessible for all employees.

Employee engagement is critical organizational requirement as organizations face globalization and recovering from the global recession. Therefore, Employee engagement has been an area of interest among many researchers (Sacks , 2006 :600-619) , (Shuck, and Wollard, 2010:89110) , (Nidan , 2016:41-47 ) , and most contemporary organizations are seeking for high levels of employee engagement to harvest many benefits, including the increasing efficiency and productivity of employees which will reflect positively in the success of the organization.

The economic, social and political importance of information transparency has gained an increasing attraction over the past decade, among academicians and practitioners alike. This has been part of a broader movement that seeks to explain and understand the role that information transparency play in enhancing employee engagement.

Based on above, the present study will analyze the role of Information Transparency on employee engagement. This study has been divided into five sections, the first section deals with the methodology of the study, the second section covers a detailed literature review on the subject matter, with more emphasis on the theoretical underpinnings of the concept of the study variables, section three covers results and findings, section four deals with the discussion of the results, and finally section five presents conclusions and suggestions.

\section{SECTION 1: METHODOLOG}

\subsection{Problem And Questions Of The Study}

The hotels sector in Erbil is one of the most important service sectors which have experienced rapid growth due to the steady expansion of the tourism sector. Therefore, the management of the hotels operating in this sector need to pay attention to 
information transparency as one of modern management concepts that all organizations must implement due to its significant role in addressing many managerial problems that may arise (Darbandi and amin ,2017:293), ( Kim and Kim , 2017:3 ) and adopt the employee engagement concept that motivate employees to harness themselves voluntarily and fully cognitively, emotionally and physically toward their job and organizations.

The problem of the study can be formulated in the following questions:

1. What is the level of information transparency in hotels sector / Erbil City?

2. What is the level of employee engagement in hotels sector / Erbil City?

3. To what extent is information transparency related to employee engagement in hotels respondent sample / Erbil City?

4. How does information transparency impact employee engagement in the hotels respondent sample / Erbil City?

\subsection{Objectives Of The Study}

1. Measuring the level of information transparency in the survived hotels.

2. Measuring employee engagement in the survived hotels.

3. Determine the relationship between information transparency and employee engagement in the survived hotels.

4. Identify the impact of information transparency on employee engagement in the survived hotels.

5. Provide a set of suggestions to enhance the levels of information transparency and employee engagement in the survived hotels.

\subsection{Importance Of The Study}

A. Academic importance : The academic importance of the current study stems from it being contributing to literature that focuses on two important topics in management literature, namely informational transparency and employee engagement. The importance of this study comes also through it is being considered as one of few researches that examined the relationship between information transparency and employee engagement in the context of hotels sector/ Erbil City.

B. Field importance : The field importance of the current study stems from its results which is expected to encourage the management in the surveyed hotels to deal with information transparency and provide surveyed hotels staff with information on the benefits of having high level of employee engagement, and how engaged employees contribute to the hotels success.

\subsection{The Default Scheme And Hypotheses Of The Study}

Figure (1) shows the default scheme of the study, which is developed based on the theoretical and conceptual framework. The default scheme contains includes two main variables: the first is information transparency as independent variable and it is onedimensional. The second is employee engagement as a dependent variable, which consists of three dimensions, namely: Emotional engagement, Cognitive engagement, and Physical engagement. The relationship between variables is one-way.

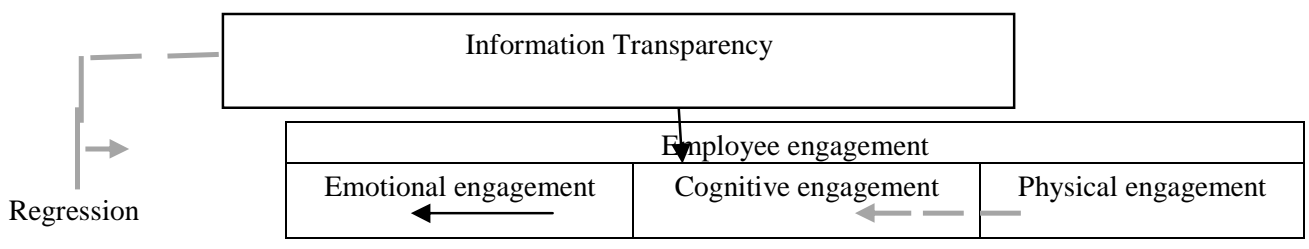

Correlation

Fig. (1) : The default scheme of the study

Source: prepared by the researchers

The following hypotheses emerge from the proposed model of the study, and it will be tested at $(0.05)$ as a defult significant level:

$\mathbf{H O}_{1}$ : There is no statistically significant relationship between Information transparency and employee engagement in the surveyed hotels. From the first main hypothesis there are three subhypothesis as follows:
$\mathbf{H O}_{1 \mathrm{a}}$ :There is no statistically significant relationship between Information transparency and emotional engagement in the surveyed hotels. $\mathbf{H O}_{\mathbf{1 b}}$ :There is no statistically significant relationship between Information transparency and cognitive engagement in the surveyed hotels. 
$\mathbf{H O}_{1 \mathrm{c}}$ :There is no statistically significant relationship between Information transparency and physical engagement in the surveyed hotels.

$\mathbf{H O}_{2}$ : There is no statistically significant impact of Information transparency on employee engagement in the surveyed hotels.

From the second main hypothesis there are three sub-hypothesis as follows:

$\mathbf{H O}_{2 \mathbf{a}}$ :There is no statistically significant impact of Information transparency on emotional engagement in the surveyed hotels.

$\mathbf{H O}_{\mathbf{2 b}}$ :There is no statistically significant impact of Information transparency on cognitive engagement in the surveyed hotels.

$\mathbf{H O}_{2 \mathrm{c}}$ : There is no statistically significant impact of Information transparency on physical engagement in the surveyed hotels.

\subsection{Data Collection Instrument}

Primary data for this study were gathered from respondents using a questionnaire consists of three basic parts are as follows: First Part looked at the demographic characteristics of respondents; the second part was devoted to measuring information transparency, while the third part was devoted to measuring employee engagement.

Information transparency was assessed using (Turilli and Floridi ,2009:105-112) standard questionnaire which consist of (12) items. Employee engagement was assessed using (Knight, 2011:90-96) standard questionnaire which consist of (15) items. This instrument has been adapted from the measurements of . Respondents in this study rated each item on a 5point Likert scale ranging from strongly disagree (1) to strongly agree (5).

In order to ascertain the ability of the questionnaire to measure the variables of the study, Reliability of the questionnaire was measured using the Cronbach alpha coefficient. The values of Cronbach's alpha was (0.97) at the total level of the scale, (0.97) for information transparency, and (0.96) for employee engagement, thus, it can be concluded that the measures have an acceptable level of reliability.

\subsection{The Population Of The Study}

The subjects of the study were all the managers in the supervisory departments of (12) selected hotels (4 five stars and 8 four stars) ; those hotels were at least five years -old and have been selected from (49) hotels (11 five stars and 38 four stars) representing the total number of the five stars and four hotels which at the duration of the study period ( lasted between December 2016 until March 2017) were listed on the General board of Tourism of Kurdistan -Iraq, therefore, the percentage of the selected hotels is $33 \%$ of the total hotels in Erbil city.

Based on the records of the Human Resources units of the surveyed hotels, the number of managers in the supervisory level is (82) managers. The reason for choosing this administrative level is that managers at this level have more knowledge than managers at other administrative levels about the reality of information transparency and employee engagement in the surveyed hotels, since they are in touch with senior managers, At the same time, they interact daily with employees at lower administrative levels.

The researchers distributed (82) questionnaires ,(80) of them i.e. (98\%) were returned, all of which are valid for analysis, and table (1) shows the distribution of respondents according to the surveyed

Table (1) :The distribution of respondents within surveyed hotel

\begin{tabular}{cccc}
\hline Number & Hotel's Name & Hotel's Classification & Number of respondents \\
\hline 1 & Van Royal Hotel & 5 stars & 7 \\
\hline 2 & Tangram Hotel Erbil & 5 stars & 9 \\
\hline 3 & Hotel Grand Swiss & 5 stars & 4 \\
\hline 4 & Cristal Erbil Hotel & 5 stars & 8 \\
\hline 5 & Lamassu Hotel & 4 stars & 6 \\
\hline 6 & Grand Palace Hotel & 4 stars & 4 \\
\hline 7 & Rodina Hotel & 4 stars & 4 \\
\hline 8 & Mariana Hotel & 4 stars & 3 \\
\hline 9 & Hotel Monaco Palace & 4 stars & 3 \\
\hline 10 & Erbil View Hotel & 4 stars & 3 \\
\hline 11 & Erbil Quartz Hotel & 4 stars \\
\hline 12 & Shahin Palace Hotel & 4 stars & 3 \\
\hline
\end{tabular}

Source: Analyzing questionnaire data 


\section{THEORETICAL FRAMWORK 2.1 Information Transparency: Definition, And Attributes}

The first obvious step for defining Information transparency is to denote exactly what is meant by the term "transparency". The term transparency originated in the field of physics, it has to do with the physical property that allows the transmission of light through a material, such as glass or plastic (Menendez-Viso ,2009:155-162). While the engineering definition of the term remains unchanged, there seems to be hardly any clarity in its meaning or usage in other disciplines (Raval, 2015:1).

Regarding information transparency it has at least two different meanings that unfortunately, are irreconcilable and hence potentially misleading: The first meaning used information transparency as forms of information visibility, which is increased by reducing or eliminating obstacles. The second meaning of information transparency is more likely to refer to a condition of information invisibility, such as when an application or computational process is said to be transparent to the user (Turillo \& Floridi, 2009:105-112)

In a definition that has been commonly used, (Hollyer et al , 2011:1191-1205) define information transparency as" the increased flow of timely and reliable economic, social and political information which is accessible to all relevant stakeholders". According to (Schnackenberg and Tomlinson ,2014:3) information transparency can be defined as "the level of information disclosure, clarity and accuracy in representations".

In this study, we shall use the term information transparency as a managerial practice includes disclose of information and provide it to all employees according to attributes of credibility, clarity, timing, and easy to free access through open communications, so that they can accomplish their tasks and participate in decision-making efficiently and effectively.

According to the previous definition, this study adopts a set of common attributes for information in order to be transparent, which were agreed upon by many researchers, these attributes are discussed briefly below (Turilli \& Floridi, 2009:105-112), (Schnackenberg and Tomlinson, 2014:1784-1810), (Alsharah , 2014 :64-77):

- Information disclosure: Refers to the process of disclosing a certain amount of information generated by an Organization. Such information can be codified by means of different media.

- Information accessibility: means information regarding all organization policies and objectives should be easy to obtain or access, by all employees and use it for their needs.

- Information clarity : means the information must be presented in a clear and understandable way to its user.

- Timelines: Means the degree to which information is up-to-date

- Information credibility : Refer to accuracy and reliability of information: Accuracy is the degree of correctness and precision with which information in an automated system represents states of the real world, Reliability deals with the truth of information or the objectivity with which it is presented.

\subsection{Employee Engagement: Definition, And Dimensions}

Employee engagement as an outcome was first defined by ethnographic researcher .(Kahn ,1990) as "the harnessing of organizational members' selves to their work roles" (Kular et al, 2008: 3). According to (Shuck and Wollard, 2009 : 90) employee engagement is an "emergent working condition and a positive cognitive, emotional and behavioral state directed toward organizational outcomes". Another definition describes employee engagement as the readiness of workers and their skills to help their organization be successful by being flexible in different situations ( Bin Shmailan , 2016: 3).

(Nidan 2016: 41) indicated that employee engagement shows the degree of how much an employee is involved, empowered, motivated and committed towards his job and organization. Personnel and Development of the United Kingdom (CIPD) provides a more comprehensive definition of employee engagement as being positively present during the performance of work by willingly contributing intellectual effort, experiencing positive emotions and meaningful connections to others (Othman and Yusof, 2016:73).

In this study, we shall use the term employee engagement as a managerial approach designed to ensure that employees are committed cognitively, emotionally and physically to their organization's goals and values, and express their skill voluntarily to contribute effectively in 
organizational success, and are able at the same time to enhance their own sense of well-being.

It is clear through literature review that researchers agreed on three dimensions of employee engagement which are Emotional engagement, Cognitive engagement, and Physical engagement (Saks ,2006:1-8), (Knight, 2011:3536), (Bin Shmailan, 2016:600-6-9).

Emotional engagement refers to the attitude an employee has towards his organization with regards to his or her feelings, these feelings could either be positive or negative (Kular et al, 2008: 6).

The cognitive aspect of employee engagement deals with the employees beliefs about organization factors such as, how it is led, by whom, and the working conditions which exist within the organization, Therefore, if these working conditions are not as expected by the employee, he tends to be affected cognitively which is detrimental to the success of the organization. (Knight, 2011: 6 ), ( Kular et al , 2008: 3).

The physical dimension of employee engagement relates to the physical energies employed by individuals in order to carry out their organizational role(s) (Kular et al, 2008: 6) ,( Knight, 2011: 6).

\subsection{The Theoretical Relationship}

Many researches have demonstrated the direct or indirect influence of information transparency on employee engagement(Yang, 2007 :91-121) ( Yang \& Grunig , 2005 : 305-325 ). Researchers also used information transparency attributes to predict the level of employee engagement ,and among those attributes :information credibility, information accuracy, openness, information timeliness, information relevance, using numerous channels (Goris et al., 2002: 664-672) , (Hoover, 2005:).

( Men 2015: 2) state that transparent organizations disclose truthful, accurate, timely, balanced, and substantial information and invite employee participation in identifying the information they need and how much information they want, thereby increasing employee's influence on the decision-making process. Such informational and participatory transparency is predicted to lead to employee satisfaction and feelings of shared control, which constitute a quality employee-organization relationship. This in turn, influences employee engagement.

According to ( Khaled 2016: 157-171) information transparency contribute to the employees' sense of belonging to the organization as participants in the decision-making, as it makes them feel the importance of their opinions by providing the information they need, thus allowing them to make proposals relating to the success of the work, as well as Information transparency helps employees actively participate to develop and build self-reliance in achieving a better quality of performance by focusing on quality and increasing productivity at work . (Alsharah , 2014 :64-77) also found that information transparency contributes in increasing employee's faith in their ability of impacting business results, and converts their interest from focusing on safety needs of and self-esteem achievement to pay attention to performance and production, hence, it is expected that information transparency will positively influence employee engagement.

\subsection{Demographic Profile}

\section{RESULTS}

Tables (2) shows the profile of the respondents. (82.5\%) of respondents are males and $17.5 \%$ are females. Their age is categorized into 3 groups with $21 \%$ aged in the range of $18-$ less than 30 years old, 58\% aged in the range 30 years - less than 45 years old , and $21 \%$ aged 45 years and more old. Regarding the academic qualification, majority of them were Bachelor holders that constitute $49 \%$, followed by Diploma holders with $30 \%$, Secondary and below holders with $21 \%$. Pertaining to working experience of the respondents at this hotel, majority of them $(57.5 \%)$ had been working with respective hotel for 3- less than 7 years, (32.5\%) had been working with the respective hotel for less than 3 years; the remaining respondents $(10 \%)$ had 7 years and more of working experience at the respective hotel. Regarding the work experience of the respondents at the hotels sector, majority of them (45\%) had been working at hotels sector for 5 less than 10 years, $34 \%$ had been working at hotels sector for less than 5 years, the remaining respondents (21\%) had 10 years and more of working experience at hotels sector. 
Table (2) :Demographic profile

\begin{tabular}{|c|c|c|c|}
\hline Variables & Descriptions & Freq. & $\%$ \\
\hline \multirow[t]{2}{*}{ Gender } & Male & 66 & 82.5 \\
\hline & Female & 14 & 17.5 \\
\hline \multirow[t]{3}{*}{ Age } & 18years - less than 30 years & 17 & 21 \\
\hline & 30 years - less than 45 years & 46 & 58 \\
\hline & 45 years and more & 17 & 21 \\
\hline \multirow[t]{4}{*}{ Academic qualification } & Secondary and below & 17 & 21 \\
\hline & Diploma & 24 & 30 \\
\hline & Bachelor & 39 & 49 \\
\hline & Master and doctoral Degree & 0 & 0 \\
\hline \multirow{3}{*}{$\begin{array}{l}\text { number of years' respondents have been working with their } \\
\text { currently e hotel }\end{array}$} & Less than 3 years & 26 & 32.5 \\
\hline & 3- less than 7 years & 46 & 57.5 \\
\hline & 7 years and more & 8 & 10 \\
\hline \multirow{3}{*}{$\begin{array}{l}\text { number of years' respondents have been working with hotels } \\
\text { sector }\end{array}$} & Less than 5 years & 27 & 34 \\
\hline & 5 - less than 10 years & 36 & 45 \\
\hline & 10 years and more & 17 & 21 \\
\hline
\end{tabular}

Source: Analyzing questionnaire data

\subsection{Descriptive Statistics}

to determine the levels of information transparency and the employee engagement Mean values were calculated and categorized into three levels that are : low (Mean values equal or less than 2.34), moderate (Mean values between 2.34 and less than 3.67), and High (Mean values of 3.7 or higher) . Standard deviation used for measuring the dispersion of a set of data from its Mean, whereas Coefficient of agreement used for ranking. The results were as follows:

\subsubsection{Descriptive Statistics Of Information Transparency}

Table (3) shows the Mean and standard deviation and Coefficient of Agreement for the information transparency, and through the table the following can be inferred:

1. Data indicates that the majority of the respondents agree that information transparency (overall), is practiced at high level in the surveyed hotels (mean $=3.88$, Standard Deviation $=1.14$ coefficient of agreement $=\% 70.62$ ).

2. The highest importance level was for paragraph (1) which states that information is presented in a clear and understandable way (Mean $=4.08$, Std . Deviation $=1.03$, coefficient of agreement $=\% 74.75$ ).

3. The lowest importance level was for the paragraph (6) in the questionnaire which states that the disclosed information helps employees to share in decision-making. (Mean $=3.68$, Std. Deviation $=1.21$, coefficient of agreement $=\% 66.41$ )

4. In general, the study results indicate that there is a high degree of adopting information transparency in the sampled hotel.

Table (3): Descriptive statistics of information transparency

\begin{tabular}{|c|c|c|c|c|c|c|}
\hline No. & Items & Mean & SD & $\begin{array}{l}\text { CA } \\
\% \\
\end{array}$ & Level & Ranking \\
\hline 1 & Information is presented in a clear and understandable way & 4.08 & 1.03 & 74.75 & High & 1 \\
\hline 2 & $\begin{array}{l}\text { The disclosed information constitutes a complete picture of the } \\
\text { hotel procedures and policies }\end{array}$ & 3.85 & 1.09 & 71.69 & High & 5 \\
\hline 3 & Information issued by the hotel management is credible & 4.06 & 1.14 & 71.92 & High & 3 \\
\hline 4 & Information is provided in suitable time. & 3.75 & 1.11 & 70.40 & High & 7 \\
\hline 5 & $\begin{array}{l}\text { The hotel management constantly updates the information and } \\
\text { circulate them to the hotel employees }\end{array}$ & 3.89 & 1.14 & 70.69 & High & 6 \\
\hline 6 & $\begin{array}{l}\text { The disclosed Information helps employees to share in decision- } \\
\text { making. }\end{array}$ & 3.68 & 1.21 & 67.12 & High & 12 \\
\hline 7 & Information is accurate & 4.05 & 1.12 & 72.35 & High & 2 \\
\hline
\end{tabular}




\begin{tabular}{|c|c|c|c|c|c|c|}
\hline 8 & $\begin{array}{l}\text { The hotel use modern and sophisticated communication } \\
\text { technologies to provide information }\end{array}$ & 3.80 & 1.13 & 70.26 & High & 8 \\
\hline 9 & $\begin{array}{l}\text { The hotel management provides open communication for } \\
\text { employees to obtain or access }\end{array}$ & 3.94 & 1.11 & 71.83 & High & 4 \\
\hline 10 & The hotel provides information to all employees without exception. & 3.90 & 1.23 & 68.46 & High & 10 \\
\hline 11 & Information is valid & 3.76 & 1.21 & 67.82 & High & 11 \\
\hline 12 & Information helps in explaining works problem. & 3.87 & 1.20 & 68.99 & High & 9 \\
\hline & information transparency(over all) & 3.88 & 1.14 & 70.62 & High & ------- \\
\hline
\end{tabular}

Source: Results of SPSS

\subsubsection{DESCRIPTIVE STATISTICS OF EMPLOYEE ENGAGEMENT}

Table (4) manifests the Mean, standard deviations and Coefficient of agreement for the employee engagement and the three dimensions of employee engagement (emotional, cognitive, and Physical engagement) in the respondent's hotels from the managers' view in the supervisory departments of the surveyed hotels. In general, the table reveals that employees in the survived hotel have moderate level of importance, since the level of employee engagement (overall ) was medium $($ Mean $=3.58$, std. $=1.14$, Coefficient of Agreement $=\% 68.16$, ) , and the level of emotional engagement ,cognitive engagement , and Physical engagement were also medium .The highest importance level was for Physical engagement with $($ Mean $=3.64, \mathrm{Std}=1.01$, coefficient of Agreement $=\% 72.25$ ) .The lowest importance level was for the emotional engagement with $($ Mean $=3.53$, std. $=1.23$, Coefficient of Agreement $=$ \%65.15).

Table (4) : Descriptive statistics of employee engagement

\begin{tabular}{lllllll}
\hline No. & Variables & M & SD & CA & Degree & Ranking \\
\hline 1 & Emotional engagement & 3.53 & 1.23 & 65.15 & Medium & 3 \\
\hline 2 & Cognitive engagement & 3.57 & 1.19 & 66.67 & Medium & 2 \\
\hline 3 & Physical engagement & 3.64 & 1.01 & 72.25 & Medium & 1 \\
\hline 4 & Employee engagement & 3.58 & 1.14 & 68.16 & Medium & $-\cdots$ \\
\hline
\end{tabular}

Source: Results of SPSS

\subsection{CORRELATION ANALYSIS}

A correlational research design was used as the study is intended to test the first hypothesis of the study, and the results of the Correlation analysis are summarized in table (5). The results reveal that the Informational transparency is highly correlated with employee engagement ,emotional engagement, cognitive engagement ,and physical engagement at level $(\mathrm{p}<0.01)$.The values of correlation coefficient range between (0.573) and (0.650), therefore the first main null hypothesis and the three sub-hypotheses that derived from the main first hypotheses were rejected, so the alternative hypotheses were accepted.

Table (5): Results of correlation analysis

\begin{tabular}{cccccc}
\hline Variables & $\begin{array}{c}\text { Emotional } \\
\text { engagement }\end{array}$ & $\begin{array}{c}\text { Cognitive } \\
\text { engagement }\end{array}$ & $\begin{array}{c}\text { Physical } \\
\text { engagement }\end{array}$ & $\begin{array}{c}\text { Employee } \\
\text { engagement }\end{array}$ & $\begin{array}{c}\text { Result of Null } \\
\text { Hypothesis }\end{array}$ \\
\hline $\begin{array}{c}\text { Information } \\
\text { transparency }\end{array}$ & $.573^{* *}$ & $.650^{* *}$ & $.594^{* *}$ & $.639^{* *}$ & Rejected \\
\hline
\end{tabular}

Notes: ** Correlation is significant at the 0.01 level (1-tailed), $n=80$.

Source: Results of SPSS 


\subsection{REGRESSION ANALYSIS}

For the purpose of testing the second hypothesis of the study, a set of simple regression analyses were used. The first simple regression analysis was carried out to find out the extent to which information transparency explained employee engagement, so it is depended on $\mathrm{R}^{2}$. Table (6) demonstrates the results According the results $41 \%$ of the variance in the values of employee engagement is explained by information transparency $\left(\mathrm{R}^{2}=0.409\right)$, and the rest of the percentage (59\%) is explained by other variables. The regression model is significant $(\mathrm{F}=$ $\begin{array}{llll}53.908, \quad \mathrm{p} & =0.000) \text {. }\end{array}$

Table (6): Results of regression analysis between information transparency and employee engagement

\begin{tabular}{lllllll}
\hline Model & Sum of Squares & Df. & Mean Square & R Square & F & Sig. \\
\hline Regression & 37.978 & 1 & 37.978 & .409 & 53.908 & $.000^{\mathrm{a}}$ \\
\cline { 1 - 5 } Residual & 54.952 & 78 & .705 & & & \\
\cline { 1 - 5 } Total & 92.930 & 79 & & & & \\
\hline
\end{tabular}

Dependent variable: Employee engagement , F tab. $(1,78)=$

Source: Results of SPSS

The second regression analysis was run to determine the impact of information transparency as independent variable on emotional engagement as dependent variable, and the results are summarized in table 7. According the results there is a statistically significant impact of Information transparency on emotional engagement, in the surveyed hotels $\left(\mathrm{R}^{2}=.328\right.$, $\begin{array}{lll}\mathrm{t}=6.177, \quad \mathrm{p}= & 0.000)\end{array}$

Table (7): Results of regression analysis between information transparency and emotional engagement

\begin{tabular}{|c|c|c|c|c|c|c|}
\hline \multirow[t]{2}{*}{ Model } & \multicolumn{2}{|c|}{ Unstandardized Coefficients } & \multirow{2}{*}{$\begin{array}{c}\begin{array}{c}\text { Standardized } \\
\text { Coefficients }\end{array} \\
\text { Beta }\end{array}$} & \multirow[t]{2}{*}{$\mathbf{R}^{2}$} & \multirow[t]{2}{*}{$\bar{t}$} & \multirow[t]{2}{*}{ Sig. } \\
\hline & $\mathrm{B}$ & Std. Error & & & & \\
\hline Constant & .821 & .453 & & & 1.814 & .073 \\
\hline $\begin{array}{l}\text { Information } \\
\text { transparency }\end{array}$ & .697 & .113 & .573 & .328 & 6.177 & .000 \\
\hline
\end{tabular}

Dependent variable: Emotional engagement , $\mathrm{t}$ tab.(79)=

Source: Results of SPSS

Looking at the impact of information transparency on cognitive engagement, the third regression analysis was performed, and table (8) shows the results. The simple regression analysis between these two variables according to the results $\left(\mathrm{R}^{2}=.423, \mathrm{t}=7.550, \mathrm{p}=0.000\right)$ indicate that there is a statistically significant impact of Information transparency on cognitive engagement, in the surveyed hotels.

Table (8): Results of regression analysis between information transparency and cognitive engagement

\begin{tabular}{lllllll}
\hline Model & \multicolumn{2}{l}{ Unstandardized Coefficients } & $\begin{array}{l}\text { Standardized } \\
\text { Coefficients }\end{array}$ & $\mathbf{R}^{2}$ & $\mathbf{t}$ & Sig. \\
\cline { 2 - 4 } & $\mathrm{B}$ & Std. Error & Beta & & 1.491 & .140 \\
\hline Constant & .605 & .406 & & .423 & 7.550 & .000 \\
\hline $\begin{array}{l}\text { Information } \\
\text { transparency }\end{array}$ & .764 & .101 & .650 & & & \\
\hline
\end{tabular}

Dependent variable: Cognitive engagement

Source: Results of SPSS

The forth regression analysis was carried out to determine the impact of information transparency on physical engagement, and the results are summarized in table (9). According the results there is a statistically significant impact of Information transparency on physical engagement, in the surveyed hotels $\left(\mathrm{R}^{2}=0.352, \mathrm{t}=6.526, \mathrm{p}=\right.$ $0.000)$. 
Table (9): Results of regression analysis between information transparency and physical engagement

\begin{tabular}{|c|c|c|c|c|c|c|}
\hline \multirow[t]{2}{*}{ Model } & \multicolumn{2}{|c|}{ Unstandardized Coefficients } & \multirow{2}{*}{$\begin{array}{l}\text { Standardized } \\
\text { Coefficients } \\
\text { Beta }\end{array}$} & \multirow[t]{2}{*}{$\overline{R^{2}}$} & \multirow[t]{2}{*}{$t$} & \multirow[t]{2}{*}{ Sig. } \\
\hline & $\mathrm{B}$ & Std. Error & & & & \\
\hline Constant & 1.335 & .365 & & & 3.658 & .000 \\
\hline $\begin{array}{l}\text { Information } \\
\text { transparency }\end{array}$ & .595 & .091 & .594 & .352 & 6.526 & .000 \\
\hline
\end{tabular}

Dependent variable: physical engagement

Source: Results of SPSS

Based on the results of simple regression, it is clear that the results showed a significant impact of Information transparency on employee engagement, cognitive engagement, emotional engagement, and physical engagement ; therefore the second main null hypothesis and the three subhypotheses that derived from the main second hypotheses were rejected, so the alternative hypotheses were accepted.

\section{DISCUSSION}

The results of descriptive statistics showed high levels of information transparency which reflects high interest by the management of survived hotels in the disclosure of information to all employees in those hotels, and provide them according to the attributes of accessibility, clarity ,time lines, and credibility . While the results of descriptive statistics showed medium level of employee engagement, which indicate that the management of the survived hotels does not give enough attention to raising the level of employee engagement among employees.

Based on the results of the correlation analysis between the information transparency and employee engagement, that have been shown to be significant and positive, it is clear that the high level of employee engagement is associated with the high level information transparency, and vice versa.This result match the view of (Robinson et al , 2004:5 ) which they described the engagement as a two-way relationship between the employer and employee.

According to the results of regression analysis, information transparency impact significantly on employee engagement, this means information transparency is one of the predictors of employee engagement, and this results provide a clear message to the managers in the surveyed hotels, which is if they want to raise the level of employee engagement among the employees in those hotels, they should focus on the practice of information transparency at high levels.

The results of regression analysis show that $41 \%$ of the variance in the values of employee engagement is explained by information transparency, although this percentage is statistically significant, however, there is a large percentage that is explained by other factors. This can be explained by the fact that employee engagement includes emotional, cognitive, and physical dimensions, Thus it can be influenced by many individual factors of the employees such as age, gender, duration of service, level of education, social status and functional factors such as working conditions, supervision patterns, promotion opportunities, flexible work arrangements, training programs, and incentive rewards, as well organizational factors such as leadership style, organizational culture , organizational structure, organizational climate, nature of communications, and prevailing human relations, etc. This view is consistent with the view of many researches e.g: (Kuler et al , 2008), (Albdour and Altarawneh ,2014: ), and May et al (2014) whom view employee engagement as situational variable influenced by many factors.

The results of this study also show that the impact of information transparency on cognitive engagement was stronger than the impact of information transparency on emotional engagement and physical engagement (based on $\mathrm{R}^{2}$ values). This means that information transparency could predict cognitive engagement greater than the prediction by emotional engagement, and physical engagement.

\section{CONCLUSIONS AND SUGGESTIONS 5.1 Conclusions}

1. There is a clear tendency among the respondents to agree that the surveyed hotels are practicing information transparency at high level, this means high level of Information disclosure, 
accessibility, Timeliness, and Information credibility.

2. The majority of the respondents agreed on the existence of medium level of employee engagement at the survived hotels, which means medium levels of emotional engagement, cognitive engagement, and physical engagement)

3. The study found that the dominant dimension of employee engagement among hotels employees is the physical dimension. This means that the employees are exert a lot of energy doing their job and ready to work too hard and overtime whenever possible, and stay until the job is done

4. The findings indicate a positive significant correlation between information transparency and employee engagement, therefore, hotels can have high level of employee engagement when they disclose information to their employees with attributes of accessibility, timeliness, and credibility.

5. This study has provided empirical evidence to support the theory, when it shows that when the organization provides high level of information transparency, employees would report high levels of engagement in their organization.

6. The results highlight the importance of information transparency in affecting the three dimensions of employee engagement (emotional engagement, cognitive engagement, and physical engagement).

7. Based on the results of the hypotheses testing , information transparency is one of the predictors of employee engagement, this means it is possible to determine the expected levels of employee engagement based on the extent of which information transparency practiced by the hotels.

\subsection{Suggestions}

1. Providing better levels of information transparency in surveyed hotels through the disseminating objective information free from distortion and indistinct, making it available and easy when needed, and update their data bases continuously to provide employees with the information they need to perform their jobs efficiently and effectively

2. Providing clear and two-way communication system between management employees, and the communication must be in varying types such as : upward, downward, lateral or informal,

3. Creating an organizational climate that encourages employees to participate in goals setting and decision-making.
4. Management of the surveyed hotels should ensure that the policies make employees more enthusiastic and excited about their job roles, as well as being positive and proud of about their job roles, and management should ensure that environments within hotels enhance employees to pay a lot of attention to their job roles and also concentrate adequately.

5. Encourage employees toward independent thinking by giving them more job autonomy, and Ensure that employees have all the resources such as physical or material, financial and information , and help employees to increase their knowledge and skills through further appropriate training.

6. Preparing special programs, open dialogue and periodical meetings with hotels employee's to pay more attention to their views, opinions, and needs .

7. Enhancing the emotional attachment of employees with their jobs by providing the reasons for the sense of job security and providing a fair system of incentives of material and moral based on efficiency and level of achievement, which leads to increase their sense of the principle of justice and increase attachment to the job

8. Taking advantage of this study scale by hotels management for periodical diagnosis of the level of information transparency and employee engagement in those hotels.

\subsection{LIMITATIONS AND FUTURE RESEARCHES}

The main limitation of this research is related to its research design. This study was based on the determination of the level of information transparency and employee engagement from the managers' point of view in the supervisory departments of the surveyed hotels , therefore, further research could be conducted to determine the level of information transparency and employee engagement form the managers' point of view in frontline of the surveyed hotels . As the sample size is small, the outcome of the study is not precisely accurate, thus there is a need to include the rest of the hotels in future studies.

This study was conducted in hospitality sector, therefore the findings may be applicable to this particular sector, future studies should various sector so that the findings can be generalized to a bigger population. This study consider only the impact of informational transparency on employee engagement, future study could add some other variables that affect employee engagement like organization climate 
,organizational culture, leadership style , and individual factors as these factors are believed to determine employee engagement.

\section{REFERENCES}

- Albdour, Ali Abbaas and Altarawneh, Ikhlas I. (2014). Employee Engagement and Organizational Commitment: Evidence from Jordan, International Journal of Business, 19 ( 2), 192-212.

- Alsharah , Atallah (2014). Extent of Commitment in Applying Managerial Transparency in Jordan Government Institutions, Public Policy and Administration Research , 3( 4), 64-77, www.iiste.org

- Bin Shmailan, Abdulwahab , S. (2016). The relationship between job satisfaction, job performance and employee engagement: An explorative study , Issues in Business Management and Economics ,4( 1), 1-8 .From http://www.journalissues.org/IBME/ http://dx.doi.org/10.15739/IBME.16.001.

- Darbandi , Houshyar And Amin, Fairoz , (2017, Qalaai Zanist Scientific Journal Vol. (2), Issue (3), June 2017 293-316.

- Goris, J.R. , Pettit, J.D. and Vaught, B.C. (2002). Organizational communication: Is it a Moderator of the relationship between job congruence and job Performance/satisfaction? International Journal of Management, 19, 664-672.

- Hollyer ,J., Rosendorff ,B.P. and Vreeland,J.R.(2011). Democracy and transparency, Journal of polit ,73(4),1191-1205.

- Hoover, G. (2005). Maintaining employee engagement when communicating difficult issues. Communication World, Nov-Dec, 25-27.

- Khaled , Serhan, K. (2016). Administrative Transparency in Public Secondary Schools in Jordan, European Scientific Journal ,12(13) ,157-171.

- Kim , Sung-Bum And Kim Dae-Young, (2017), Antecedents Of Corporate Reputation In The Hotel Industry: The Moderating Role Of Transparency , Sustainability Journal, vol. (9), ), Issue (6), June pp: 215. www.mdpi.com/journal/sustainability

- Knight , Robert (2011). Employee Engagement ,A study of employee engagement at Topaz"s ,South Dublin Region Service Stations, A dissertation submitted in partial fulfilment of the requirements of the Masters in Human Resource Management , National College of Ireland, Dublin , Ireland.

- Kular S., Mark G., Chris R., Emma S., and Katie T. (2008). Employee Engagement: A Literature Review. Kingston Business School, Kingston University Working Paper Series, No 19

- May, D.R. ,Gilson, R.L. and Harter, L.M. (2014) The psychological conditions of meaningfulness, safety and availability and the engagement of the human spirit at work', Journal of Occupational and Organizational Psychology, 77, 11-37.

- Men , L. R. (2015). Employee Engagement in Relation to Employee-Organization Relationships and Internal Reputation: Effects of Leadership Communication. Public Relations Journal, 9(2). From http://www.prsa.org/Intelligence/PRJournal/Vo19/No2/. - Menendez-Viso, A.(2009). Black and White Transparency Contradictions of a Moral Metaphor, Ethics and Information Technology, 11, 155-162

- Nidan , Priyadarshni (2016). To study the impact of employee engagement on employee productivity and motivational level of employee in retail sector, IOSR Journal of Business and Management Management, 41-47. From, www.iosrjournals.org IES

- Othman , Abdul Kadir and Yusof , Siti Noraini (2016). The Mediating Effect of Employee Engagement on the Relationship between Work and Organizational Factors and Employee Satisfaction at Selected Hotels , Journal of Applied Environmental and Biological Sciences , 6(5S),73-81 . From www.textroad.com

- Raval ,vasant (2015). Information Ethics: Transparency and the IT Professional, ISACA journal, 6, 1-4

- Robinson, D., Perryman S., and Hayday S.( 2004). The Drivers of Employee Engagement, Institute for Employment Studies, Brighton. From http://www.employment-studies.co.uk/

- Saks, A.M.,( 2006).Antecedents and Consequences of Employee Engagement, Journal Of Managerial Psychology, 21(7), 600-619.

- Schnackenberg, Andrew K. and Tomlinson Edward C. (2014). Organizational Transparency: A New Perspective on Managing Trust in OrganizationStakeholder Relationships , Journal of Management, 42( 7), 1784-1810

- Shuck, B. and Wollard, K.K. (2009). Employee engagement and HRD: a seminal review of the foundations. Human Resource Development Review, 9 (1), 89-110.

- Turilli, M. and Floridi L. (2009). The Ethics of Information Transparency, journal of Ethics and Information Technology ,11, 105-112

- Yang, S. (2007). An integrated model for organization - public relational outcomes ,Organizational reputation and their antecedents. Journal of Public Relations Research, 19, 91-121.

- Yang, S., and Grunig, J. E. (2005). The effects of organization-public relationship Outcomes on cognitive representations of organizations and overall Evaluations of organizational performance. Journal of Communication Management, 9, 305-325. 